\title{
El beso de la mujer araña: gênero, sexualidade e subversão
}

Anselmo Peres Alós ${ }^{1}$

\section{El beso de la mujer araña: a construção da diegese romanesca a partir de intertextos fílmicos}

El beso de la mujer araña, provavelmente o mais conhecido de todos os romances do argentino Manuel Puig (1976/1994), explora a relação intersubjetiva entre um preso político e um homossexual, relação travada dentro de uma cela. É considerado pela crítica como o momento de plena maturidade do escritor argentino Manuel Puig. Em agosto de 1981, esta obra é adaptada para o palco pelo próprio Puig e encenada no Teatro Ipanema, sob a direção de Ivan Albuquerque. Cabe lembrar que Hector Babenco, alguns anos depois, levou a narrativa para as telas do cinema. A linguagem dramático-teatral já está presente na própria estrutura do livro (que se constitui como diálogo, sem a intervenção de um narrador expresso), tal como a linguagem cinematográfica (presente como um texto palimpséstico transformado nas falas de Molina). Entretanto, o recurso mais singular desta obra é a utilização de notas de rodapé, que, paralelamente ao texto, ocupam-se de descrever a evolução do pensamento médico e psicanalítico sobre a homossexualidade desde o final do século XIX até o momento histórico contemporâneo ao romance.

Funcionando aparentemente como uma narrativa sem narrador, Puig escreve um romance de estrutura dramática, no qual é estabelecida uma permanente tensão entre os dois protagonistas, Molina e Valentín. A maior parte da ação passa-se dentro de uma cela, em uma penitenciária argentina situada na cidade de Buenos Aires. Molina é um homossexual cumprindo pena por corrupção de menores. Um homem que se declina no feminino, tal como quando - ao lembrar de um antigo amor - afirma a Valentín: "si, perdóname, pero cuando hablo de él yo no puedo hablar como hombre, porque no me siento hombre" (Puig, 1994, p. 69). Valentín, por sua vez, é um preso político, militante marxista de esquerda, como deixa claro em suas próprias palavras: "mis ideales, ... el marxismo, si

1 Doutor em literatura comparada e professor do Programa de Pós-Graduação em Letras da Universidade Federal de Santa Maria (UFSM), Santa Maria, RS, Brasil. E-mail: anselmoperesalos@gmail.com 
queres que te defina todo con una palabra. Y ese placer [o prazer da luta revolucionária] lo puedo sentir en cualquier parte, acá mismo en esta celda, y hasta en la tortura. Y ésa es mi fuerza" (Puig, 1994, p. 34). Se para Molina a vida é um grande palco, um ritual reiterado de poses e artifícios, para Valentín o sentido da existência é dado pela luta por um mundo mais justo, pela derrocada dos opressores e pela construção do socialismo. As diferentes modalizações do discurso não criam apenas diferentes perspectivas para se observar o mundo: criam mundos diversos, diferentes, por vezes incompatíveis.

Pouco a pouco, ambos começam a travar longos diálogos, que acabam por modificar as concepções pessoais de gênero, sexualidade e política tanto de Valentín quanto de Molina. As primeiras conversas entre estes dois personagens têm como pauta os filmes assistidos por Molina. Tal como a Sheerazade das Mil e uma noites, Molina passa as últimas horas antes do sono contando a Valentín as histórias de filmes que assistiu ao longo de sua vida. Todos os filmes narrados por Molina trazem um ponto comum: o estereótipo da femme fatale, da mulher-objeto, da mulher animalizada. Na primeira dessas narrações, é possível identificar a animalização e a objetificação da mulher por meio da associação da imagem feminina com a imagem da pantera, da besta felina selvagem e devoradora de homens. Molina, neste trecho, descreve a gênese das mulheres-pantera:

Ella no se animaba a mirarlo en los ojos, coloca la cabeza sobre las rodillas de él. Entonces empieza a contar que había una leyenda en su aldea de la montaña, que siempre la ha aterrorizado, desde chica. Y eso yo no me acuerdo bien como era, algo de la Edad Media, que una vez esas aldeas quedaron aisladas por la nieve meses y meses, y se morían de hambre, y que todos los hombres se habían ido a la guerra, algo así, y las fieras del bosque llegaban hambrientas hasta las casas, no me acuerdo bien, y el diablo se apareció y pidió que saliera una mujer si querían que él les trajese comida, y salió una mujer, la más valiente, y el diablo tenía al lado una pantera enfurecida, y esa mujer hizo un pacto con el diablo, para no morir, y no sé qué pasó y la mujer tuvo una hija con cara de gata. Y cuando volvieron los cruzados de la Guerra Santa, el soldado que estaba casado con esa mujer entró a la casa y cuando la fue a besar ella lo despedazó vivo, como una pantera lo hubiese hecho (Puig, 1994, p. 18). 
É a partir das análises que realizam sobre a mulher-pantera que, aos poucos, ambos começam a contar pequenos eventos de suas vidas particulares. Como já afirmou Laura Rice-Sayre (1989), a narrativa de Molina está baseada no filme de terror Cat people, de Jacques Tourneau. As reações expressas por Molina e Valentín acerca do filme expressam as maneiras pelas quais esses dois sujeitos se colocam no mundo: Molina identifica-se com o sentimentalismo da narrativa, enquanto Valentín deixa clara sua recusa da sexualidade e do amor em prol da causa revolucionária:

Bueno, todo me lo aguanto... porque hay una planificación. Está lo importante, que es la revolución social, y lo secundario, que son los placeres de los sentidos. Mientras dure la lucha, que durará talvez toda mi vida, no me conviene cultivar los placeres de los sentidos, ¿te das cuenta?, porque son, de verdad, secundarios para mí. El gran placer es otro, el de saber que estoy al servicio de lo más noble, que es... bueno... todas mis ideas (Puig, 1994, p. 33).

O segundo filme que Molina narra a Valentín é de origem alemã, um longa-metragem de ideário nazista, que conta a história de uma jovem alsaciana (região fronteiriça entre a Alemanha e a França, pertencente ao território desta última) que se sente dividida entre o patriotismo francês e o amor a um oficial alemão. Leni Lamaison, como é chamada a personagem alsaciana, é cantora de uma boate francesa, e em uma de suas apresentações conhece o referido oficial. Molina entusiasma-se com o enredo desse filme, o que desperta o ódio de Valentín, que não vê no referido filme nada além de "una imundícia nazi" (Puig, 1994, p. 63). É por ocasião desse filme que fica expressa a alienação de Molina; o filme que embasa a segunda narrativa de Molina é fortemente marcado como um filme de divulgação das idéias nazistas. A própria narração de Molina traz elementos que comprovam a presença da ideologia do Terceiro Reich: a descrição do açougueiro - trabalhador do mercado negro de alimentos - assevera isso:

- Estamos en Paris, hace ya unos meses que los alemanes la tienen ocupada. Las tropas nazis pasan bien por el medio del Arco del Triunfo. En todas partes, como en las Tullerías y esas cosas, está flameando la bandera con la cruz esvástica. Desfilan los soldados, todos rubios, bien lindos, y las chicas francesas los aplauden al pasar. Hay una tropa de pocos soldados que va por una callecita típica, y entra en una carnicería, el carnicero es un viejo de nariz 
ganchuda, con la cabeza en punta, y un gorrito ahí en el casco puntiagudo.

- Como un rabino.

- Y cara de maldito. Y le viene un miedo bárbaro cuando ve a los soldados que entran y le empiezan a revistar todo.

- ¿Qué le revistan?

- Todo, y le encuentran un sótano secreto lleno de mercaderías acaparadas, que por supuesto vienen del mercado negro. Y se junta la chusma afuera [...] y dicen que en Europa ya no va a haber hambre, porque los alemanes van a terminar con los explotadores del pueblo (Puig, 1994, p. 55).

Valentín, ao contrário de Molina, apercebe-se do cunho político imbricado nesse filme. Tal questão fica clara por ocasião da publicidade oficial dos Estudos Tobias Berlin, que surge sob a forma de nota de rodapé no romance (Puig, 1994, p. 88-94). Por causa disso, ambos discutem, uma vez que Molina sente-se ofendido ao ouvir Valentín julgar o filme em questão apenas como propaganda nazista:

- Me ofendes porque te... te creés que no... no me doy cuenta que es propaganda na... nazi, pero se a mi me gusta es porque está bien hecha [la película], aparte de eso es una obra de arte, vos no sabés po... porque no la viste (Puig, 1994, p. 63).

Molina enfurece-se com Valentín, sentindo-se humilhado porque o jovem revolucionário o considera um maricón sem instrução nem posição social. Molina, sentindo-se injuriado, vinga-se de Valentín privando-o da sua terceira narrativa - romântica e melodramática ao extremo - na qual, depois da segunda guerra mundial, um aviador desfigurado e uma jovem empregada órfã apaixonam-se e encontram a felicidade. Essa narrativa é grafada em itálico, em um ritmo contínuo e com uma sintaxe própria, de maneira a marcar fortemente o fluxo de consciência de Molina. Entretanto, Valentín é afligido por uma violenta infecção intestinal, o que leva Molina a se compadecer de seu companheiro de cela e voltar a narrar filmes para o mesmo, após ter jurado não mais fazê-lo: "Había jurado que no te iba a contar otra película. Ahora voy al infierno por no cumplir la palabra" (Puig, 1994, p. 117). Molina começa então a contar a história de um filme sobre automobilismo, que se passa no sul da França. A narrativa retrata "un muchacho sudamericano muy rico, un play boy, de esos hijos de estancieros que tienen plantaciones de bananas, y están en las pruebas, 
y le explica a otro que él no corre para ninguna marca de autos porque son todos unos explotadores del pueblo los fabricantes" (Puig, 1994, p. 118). Ao fazer com que o jovem guerrilheiro urbano recorde-se da mãe e da família, Valentín percebe que - em última análise - é um traidor dos valores de sua família e de sua classe de origem.

As contradições das concepções revolucionárias de Valentín ficam expressas ao final do capítulo seis, durante o seu sono. Tal como por ocasião do monólogo interior de Molina, o sonho de Valentín aparece frisado em itálico, com a sintaxe típica do fluxo de consciência. No início do devaneio onírico de Valentín, a imagem da mulher ideal expressa por este mostra uma série de contradições: ela deve possuir as qualificações esperadas de uma mulher da classe burguesa, ao mesmo tempo que deve também ter conhecimentos marxistas e ser simpatizante das concepções revolucionárias de Valentín:

- una mujer europea, una mujer inteligente, una mujer hermosa, una mujer educada, una mujer con conocimientos de marxismo, una mujer a que no es preciso explicarle todo desde el abc, una mujer que con preguntas inteligentes estimula el pensamiento del hombre, una mujer de moral insobornable, una mujer de gusto impecable, una mujer de vestir discreto y elegante, una mujer joven y madura a la vez, una mujer con conocimientos de bebidas, una mujer que sabe elegir el menú adecuado, una mujer que sabe ordenar el vino adecuado, una mujer que sabe recibir en su casa, una mujer que sabe dar órdenes al personal del servicio, una mujer que sabe organizar un recibimiento para cien personas (Puig, 1994, p. 128).

Ora, fica muito claro aqui que, se por um lado, Valentín transcende sua origem de classe, por outro, ele ainda carrega muitos dos preconceitos de sua classe de origem. Ao mesmo tempo em que esta mulher idealizada tem de estimular o pensamento de seu companheiro e ser versada na tradição do pensamento de esquerda, tem também de saber escolher o vinho adequado e entender de bebidas, saber receber cem convidados e dar ordens aos empregados da casa. Ou seja, para Valentín, a mulher ideal é aquela que mantém a ordem na esfera privada, que tem de ocupar seu papel de sagrada guardiã do espaço doméstico, uma concepção de papel social feminino extremamente burguesa, que não condiz com as concepções igualitárias e do movimento revolucionário.

O oitavo capítulo do romance, por sua vez, estrutura-se enquanto peça fundamental para a compreensão da narrativa de Puig. Nele, é 
estabelecido um diálogo entre Molina (designado como procesado) e o diretor da penitenciária (designado como director). Neste diálogo, o leitor é informado de que Molina é um agente infiltrado na cela de Valentín, e que sua missão é se aproximar do jovem guerrilheiro para arrancar informações sobre seus outros companheiros revolucionários. Em caso de sucesso em sua missão, Molina receberia o perdão pela acusação de abuso sexual de menores e conquistaria sua liberdade novamente. No capítulo nove, entra em cena novamente a voz narrativa de Molina, contando os filmes assistidos, uma vez mais, a seu companheiro de cela. O ponto de apoio para a história, desta vez, é o filme I walked with a zombie, também de Jacques Toureau. A questão da determinação da subjetividade pelo meio social e do controle dos destinos humanos por forças que estão além do domínio pessoal é discutida a partir do mote do sobrenatural e dos sortilégios. É a partir da religião vodu que se dá a inserção desse tópico na diegese do romance.

Ao final dessa narrativa, Molina conta a Valentín que, após uma conversa com seu advogado, ficara sabendo da possibilidade de voltar à liberdade. Conta também que tem muito medo de voltar para a sua vida cotidiana, mesmo tendo muitas "amigas" fora da prisão:

- Si, tengo amigas locas como yo, pero para pasar un rato, para reírnos un poco. Pero en cuanto nos ponemos dramáticas... nos huimos una de la otra. Porque ya te conté cómo es, que una se ve reflejada en la otra y sale espantada. Nos deprimimos como perras, vos no te imaginas (Puig, 1994, p. 218).

Molina põe-se muito deprimido nesse momento. Valentín passa a acariciá-lo, tentando consolar o companheiro, e tais carícias vão crescendo de maneira que ambos acabam realizando o intercurso sexual. Esta relação é um marco importante na narrativa, pois é o ponto alto a partir do qual ambos os protagonistas saem transformados: ao mesmo tempo em que Valentín reconhece seus preconceitos sexistas e homofóbicos, tentando adotar novos comportamentos, Molina conscientiza-se do importante papel da revolução e aceita uma missão: a de levar informações de Valentín aos outros companheiros revolucionários. Este também é o ponto alto no que se refere à desestabilização da crença de Valentín a respeito do papel secundário dos prazeres dos sentidos na revolução, pois este enxerga a importância de uma revolução não apenas que liberte a exploração da burguesia pelo proletariado, mas também de uma revolução de costumes, de 
forma a reformular a ideia de uma mulher ideal e de sua colocação na sociedade (ideia que ele mesmo apresenta por ocasião de seu sonho):

- Tengo una curiosidad... ¿te daba mucha repulsión darme un beso?

- Uhmm... Debe haber sido de miedo que te convirtieras en pantera, como aquella de la primera película que me contaste.

- Yo no soy la mujer pantera.

- Es cierto, no sos la mujer pantera.

- Es muy triste ser mujer pantera, nadie la puede besar. Ni nada.

- Vos sos la mujer araña, que atrapa a los hombres en su tela.

- ¡Qué lindo! Eso sí me gusta! (Puig, 1994, p. 264-265).

Ao reconhecer em Molina uma mulher-aranha, Valentín rompe com o contínuo sexo-gênero-desejo. Molina é lido como uma personagem mulher, porque performativamente constrói esta identidade, que é reconhecida por Valentín. Mesmo tendo nascido homem, Molina consegue uma inserção social como um sujeito declinado no gênero feminino. E é por compreender a performatividade ${ }^{2}$ da identidade sexual de Molina que Valentín permite-se um envolvimento amoroso. Embora tal envolvimento não transforme o jovem guerrilheiro em um homossexual, tal relação provoca um deslocamento das concepções de sexualidade e gênero de Valentín. Valentín não consegue romper de um todo com os preceitos que associam a passividade com o feminino e a atividade com o masculino, mas reconhece na passividade e no feminino uma positividade que, em vez de submeter o feminino ao masculino, coloca-os lado a lado, repudiando assim qualquer tipo de exploração sexual:

\footnotetext{
${ }^{2}$ Para Judith Butler, a identidade sexual e a identidade de gênero não se configuram como dados estáveis ou materiais, mas, sim, como o efeito de um conjunto de práticas reiteráveis - isto é, de natureza citacional - em contraponto a uma norma idealizada e heteronormativa. Butler chega a essa discussão ao problematizar o status da feminilidade reivindicada por mulheres transexuais, travestis e drag queens. De acordo com Butler, "a performance da drag brinca com a distinção entre a anatomia do performista e o gênero que está sendo performativizado. Mas estamos, na verdade, na presença de três dimensões contingentes da corporeidade significante: sexo anatômico, identidade de gênero e performance de gênero. Se a anatomia do performista já é distinta de seu gênero, e se os dois se distinguem do gênero da performance, então a performance sugere uma dissonância não só entre sexo e performance [...]. Ao imitar o gênero, a drag revela implicitamente a estrutura imitativa do próprio gênero - assim como sua contingência. Aliás, parte do prazer e da vertigem da performance está no reconhecimento da contingência radical da relação entre sexo e gênero diante das configurações culturais de unidades causais que normalmente são supostas naturais e necessárias" (Butler, 2003, p. 196).
} 
- Pero si un hombre... es mi marido, él tiene que mandar, para que se sienta bien. Eso es natural, porque él entonces... es el hombre de la casa.

- No, el hombre de la casa y la mujer de la casa tienen que estar a la par. Si no, eso es una explotación.

- Entonces no tiene gracia.

- ¿Qué?

- Bueno, esto es muy íntimo, pero ya que querés saber... La gracia está en que cuando un hombre te abraza... le tengas un poco de miedo.

- No, eso está mal. Quién te habrá puesto esa idea en la cabeza, está muy mal eso.

- Pero yo lo siento así.

- Vos no lo sentís así, te hicieron el cuento del tío los que te llenaron la cabeza con esas macanas. Para ser mujer no hay que ser... qué sé yo... mártir. Mirá... si no fuera porque debe doler mucho te pediría que me lo hicieras vos a mí, para demostrarte que eso, ser macho, no da derecho a nada (Puig, 1994, p. 246-247).

Ao contrário de Molina, que vê os papéis femininos sob o prisma hollywoodiano, Valentín não somente percebe a arbitrariedade de definir a mulher como um sujeito hierarquicamente inferior ao homem, como intui também o funcionamento das tecnologias de gênero. Teresa de Lauretis sublinha que o cinema, a televisão e outros mass media funcionam não apenas representando a mulher, mas, ao realizar determinada representação da mulher, transformam-na em uma realidade social, pois é através dessas representações que se dá a construção das possibilidades identitárias. Molina, tendo acesso apenas aos constructos discursivos que representam a mulher como um sujeito frágil que deve submeter-se ao homem (tal como as heroínas dos filmes que narra para Valentín), mostra dificuldades em se aceitar como um sujeito pleno, que não tem necessariamente de ser submisso aos caprichos de um homem.

Finalmente, no último dos filmes narrados por Molina, um homem e uma mulher cruzam seus caminhos em um baile de máscaras. Apesar dos esforços do cavalheiro, ela não revela sua verdadeira identidade. Ele, que é um repórter, está preparando um artigo bombástico sobre o passado de uma mulher da alta sociedade, antiga atriz escandalosa que saiu de cena há algum tempo. Organizando o material para seu artigo, reconhece nas fotos da atriz a mulher que conheceu no baile. Protegida 
pelo marido ciumento, um grande figurão da máfia, a atriz acaba aceitando um segundo encontro com o jornalista. No final do filme, a atriz abre mão do dinheiro e da segurança que tinha com o marido, ainda que o jornalista não aceite ficar com ela. Como última cena desta narrativa fílmica, ela termina sozinha, caminhando e chorando, mas com um sereno e feliz sorriso nos lábios. Valentín não consegue compreender a razão pela qual Molina considera tão bela esta história:

- Qué final más enigmático, ¿verdad?

- No, está bien, es lo mejor de la película.

- ¿Y por qué?

- Quiere decir que aunque ella se haya quedado sin nada, está contenta de haber tenido por lo menos una relación verdadera en la vida, aunque ya se hay terminado (Puig, 1994, p. 263).

Isso confirma o poder das tecnologias de gênero de legitimar construções identitárias. ${ }^{3}$ Valentín, por ter construído sua identidade dentro de um sistema de valores no qual a liberdade é a maior conquista e a busca pela felicidade o motivo da luta revolucionária, não consegue compreender o conformismo feliz de Molina. Mesmo tentando convencer seu companheiro de cárcere de que não necessita rebaixar-se ou conformar-se por seu gênero sexual, ainda assim estabelece uma relação de respeito com relação ao outro. Tal tipo de posicionamento frente ao outro e à diversidade, mesmo quando não se consegue compreender esse outro, configura um fenômeno que poderia ser denominado de ética da alteridade. Este reconhecimento do outro como um igual também foi sublinhado nas análises realizadas por Claudia Kozak, ao afirmar que "la narrativa de Puig se mostra como una máquina que funciona gracias a una lógica compleja. Tal lógica instaura un tipo de pensamiento otro, no habitual: una mirada diferencial. Las novelas de Puig se dejan mirar por tal mirada" (Kozak, 1991, p. 174). Neste novo tipo de relação intersubjetiva, a partir do reconhecimento do outro não como um a menos (logo, hierarquicamente inferior), mas como um sujeito igual em seu estatuto de sujeito, (ainda que diferente nas suas especificidades), um novo tipo de relação ética

\footnotetext{
${ }^{3}$ Teresa de Lauretis reformula a noção de tecnologias da sexualidade desenvolvida por Michel Foucault no primeiro volume de Histoire de la sexualité (1976), apontando para o fato de o autor francês ter ignorado completamente os dispositivos de produção social do gênero em sua discussão. A partir daí, Teresa de Lauretis propõe a discussão de tecnologias de gênero, em analogia suplementar às tecnologias da sexualidade. Conferir, a esse respeito, Teresa de Lauretis (1984; 1987).
} 
pode ser estabelecido. Os sujeitos ex-cêntricos ${ }^{4}$ são, deste modo, colocados ao lado de, e não sob a lógica do mesmo.

Ao final do romance de Puig, Molina é libertado, mas continua sendo vigiado pela polícia de Buenos Aires. Ao travar contato com os companheiros revolucionários de Valentín, a polícia abre fogo. O grupo de guerrilheiros acaba então se vendo obrigado a atirar em Molina, impedindo que a polícia o reconduzisse à cadeia, onde acabaria sendo torturado e forçado a confessar tudo o que sabia a respeito do movimento no qual Valentín está envolvido. Este último, torturado na prisão depois desse evento, adormece sob o efeito de uma dose de morfina e sonha com Marta, sonho este perpassado por elementos do cinema hollywoodiano, assim como de reflexões acerca das similaridades entre a libertação política e a libertação sexual. Se de um lado Molina deixa a alienação para morrer em uma missão revolucionária, Valentín, mesmo estando ainda preso e sendo torturado, liberta-se de seus preconceitos de gênero e sexualidade (oriundos de sua classe de origem), reconhecendo que a luta contra a opressão sexual é tão importante e politicamente marcada quanto a luta que conduzirá à libertação política do proletariado.

\section{Dos paratextos ao funcionamento da focalização}

A partir do terceiro capítulo - no qual Valentín pede a Molina para falar sobre sua vida e suas preferências sexuais -, surge a primeira de uma série de notas de rodapé. Tais notas, funcionando como paratextos, ${ }^{5}$ agem como lanternas que removem da obscuridade os interditos entre Molina e Valentín: "Creo que para comprenderte necesito saber qué es eso lo que te pasa. Si estamos en esta celda juntos

\footnotetext{
${ }^{4}$ Linda Hutcheon aponta a emersão dos sujeitos ex-cêntricos (aqueles que não estão mais, ou nunca estiveram, no centro ocupado pelo mito de um sujeito universal), sinalizando, contudo, sua permanência residual nas práticas culturais de significação pós-modernas como uma ficção de ordem: "o centro não pode permanecer, mas ainda é uma atraente ficção de ordem e unidade que a arte e a teoria pós-modernas continuam a explorar e a subverter" (Hutcheon, 1991, p. 88).

5 “A paratextualidade constitui-se pela relação - geralmente menos explícita e mais distante - que no conjunto formado por uma obra literária (o texto propriamente dito) mantém com o que não se pode nomear senão como o seu paratexto: prefácios, posfácios, advertências, introduções, etc.; notas marginais, de rodapés, ou finais; epígrafes, ilustrações, [...] que fornecem ao texto um entorno (variável) e por vezes um comentário oficial ou oficioso, cujo leitor mais purista e menos dado à erudição externa não dispõe tão facilmente" (Genette, 1982, p. 10, tradução nossa).
} 
mejor es que nos comprendamos, y yo de gente de tus inclinaciones sé muy poco*" (PUIG, 1994, p. 65-66).

$\mathrm{O}$ asterisco ao final da frase, no texto original do romance, remete a uma nota de rodapé que fala de uma série de teorizações de ordem psicológica e psicanalítica que se ocupam em tentar explicar a gênese da homossexualidade. É o primeiro paratexto a emergir no romance; mais adiante será visto o papel estrutural deste tipo de recurso no fluxo da narrativa. Tais notas, sucedendo-se ao longo do romance, configuram um histórico das teorias sobre a homossexualidade: é como se o narrador do romance estivesse realizando uma arqueologia (no sentido foucaultiano do termo), pois ao organizar em notas os diferentes modos de se pensar a homossexualidade, ele elabora uma história descontínua das diferentes modulações discursivas que cercearam esse objeto nos discursos clínico, psicológico e psicanalítico. Assim, Puig cita nomes como os de D. J. West, T. Gibbons, S. Lewis, Sigmund Freud, W. Reich, Anna Freud, O. Fenichel, Herbert Marcuse, Dennis Altman, Otto Rank, Rattray Taylor, Norman Brown, Kate Millet e J. C. Unin. Não apenas expondo as teorias desses pensadores, mas também algumas das polêmicas levantadas por eles, Puig desenvolve paratextualmente uma linha evolutiva que vai das teorias clínicas da homossexualidade (que a consideravam uma disfunção hormonal), passando pela psicopatologia, pela psicanálise e finalmente chegando a formulações que começam a questionar não as causas da homossexualidade, mas o regime de exclusão social ao qual ela está submetida (H. Marcuse e K. Millet), politizando assim a homossexualidade e a expressão do desejo pelo mesmo.

Esses paratextos vão refletir o desenvolvimento das concepções de homossexualidade de Valentín, que, da homofobia manifesta no início da narrativa, passa a um envolvimento sexo-afetivo com Molina ao final do romance. Molina, por sua vez, ao travar contato intelecto-afetivo com Valentín, passa a preocupar-se com o destino político de seu país, envolvendo-se com a organização revolucionária da qual seu companheiro de cela faz parte. Enfim, indo da patologia orgânica à resistência política, esses paratextos dão conta da evolução sexual e política de ambos os personagens. Partindo-se do pressuposto de que Molina é um homossexual de família humilde, e de que não possui grandes conhecimentos de teoria política, e também de que Valentín é um filho da burguesia que opta pela revolução e pelo marxismo, é importante o papel que tais notas cumprem na narrativa. Tendo elas o 
mesmo acento erudito que as críticas de Valentín aos enredos melodramáticos das histórias de Molina, elas compensam a assimetria existente entre os discursos dos dois protagonistas da narrativa. Isso indica a presença de um focalizador externo ${ }^{6}$ que se esmera em manter tanto as construções identitárias de Valentín quanto as de Molina dotadas de legitimidade, assegurando, desta maneira, a possibilidade de crescimento dos dois personagens no interior da fábula.

Em outras palavras, esses paratextos funcionam como um elemento importante também para caracterizar esse texto como uma narrativa romanesca. Ainda que em toda a extensão da narrativa haja apenas falas pontuadas por travessão (o que caracteriza a predominância absoluta do discurso direto), não existem marcações (um tipo de paratexto típico da estrutura do gênero dramático, com indicações relativas aos elementos cênicos e às tomadas de luz, por exemplo). Dado o próprio caráter formal das marcações, assim como sua função dentro do texto dramático, as notas do romance de Puig não podem ser consideradas como marcações, visto que não dão conta da organização de elementos cênicos, mas, sim, de um discurso paralelo fundamental para o encadeamento de efeitos no corpo da própria narrativa, e não de efeitos de palco ou de montagem.

Ora, não há a presença de um narrador, tal como entendido pela teoria literária, a presidir e a organizar as descrições do espaço, a caracterizar os actantes (que não são senão funções dentro da fábula) em personagens com traços distintivos de conduta e personalidade. Claudia Kozak (1991), ao realizar sua leitura de La trahición de Rita Rayworth, romance de Puig anterior a El beso de la mujer araña, identifica a desconstrução do narrador afirmando que:

La narrativa de Puig pone en cuestión categorías narrativas tradicionales como las de autor y narrador. A la idea de autor se opone la de un sujeto de la escritura que maneja hilos por detrás de un telón, sin lugar fijo ni voz propia, concepto vanguardista por excelencia. A la categoría de narrador omnisciente tradicional se opone o un lugar vacío, o un narrador en tercera persona

\footnotetext{
${ }^{6}$ A noção de focalizador aqui evocada surge do trabalho de Mieke Bal, no momento em que ela retoma e aprofunda a discussão sobre a focalização proposta por Gérard Genette em Figures III (1972), ao mesmo tempo que critica e refuta a noção de implied reader, proposta por Wayne Booth em The rethoric of fiction (1983) e muito difundida por Seymour Chatman a partir de seus livros Story and discourse (1978) e Coming to terms (1990). Uma retomada recente que reavalia e problematiza tanto a proposta de Genette quanto a de Bal pode ser encontrada em The implied author: concept and controversy (2006), de Tom Kindt e Hans-Harald Müller.
} 
desdoblada en múltiples junciones: narrador descriptivo hiperobjectivo, narrador titulador, narrador relator, etc. Asimismo esta narrativa [La traición de Rita Rayworth] experimenta con variaciones del monólogo interior y del fluir de la conciencia (nada más "moderno") y expone al fragmento y las mezclas como categorías artísticas privilegiadas (Kozak 1991, p. 174). ${ }^{7}$

Tal inovação provém, possivelmente, da familiaridade de Puig com as convenções formais do gênero textual cinematográfico, o roteiro, no qual o lugar do narrador é substituído pela perspectiva da câmera, deixando na estrutura diegética um lugar vazio, não ocupado pelo narrador. Salientase aqui, entretanto, que essa inovação formal introduzida por Puig nesta narrativa tem uma função estratégica muito importante: ao tentar evitar, com todas as forças, a construção de uma voz que se caracterize como um narrador, os personagens ganham mais autonomia na economia narrativa, e a construção da diegese se dá de uma forma fragmentária na qual são privilegiadas as vozes dos personagens. Com esse recurso, a estrutruração da passagem do tempo em El beso de la mujer araña é dada pelo ritmo da oralidade, desencadeada pela linearidade temporal que o diálogo ocupa no tempo. Os próprios personagens, a partir daquilo que afirmam, negam, desejam ou sonham, constroem-se dentro de uma lógica performativa: somente a partir dos enunciados que são reiterados pelos personagens é que se pode erigir uma imagem de Valentín e de Molina como consciências individualizadas.

Não se pode, contudo, perder de vista o fato de que Valentín e Molina são sujeitos constituídos por palavras, e não indivíduos cuja existência é física, por mais tautológica que uma consideração desse tipo sobre um personagem possa parecer. Logo, há uma instância maior que regula os modos pelos quais esses personagens são colocados em cena: a instância da focalização. No romance de Puig, dado o apagamento da instância narrativa (o narrador), voz que geralmente media a organização da diegese, o focalizador torna-se a instância máxima de

\footnotetext{
${ }^{7}$ Entretanto, as considerações de Kozak não podem ser meramente deslocadas para a análise de $E l$ beso de la mujer araña pois, em seu artigo, sua preocupação é realizar uma análise da obra de Puig a partir da noção bakhtiniana de gêneros discursivos (Bakhtin, 1993, 1997, 1981). Ainda que seja uma análise bastante instigante, Kozak não se utiliza da categoria focalização, fundamental para a compreensão do funcionamento daquilo que ela designa como "sujeito da escritura". Esta é a direção principal que as considerações aqui realizadas a respeito da técnica narrativa de Puig divergem daquelas desenvolvidas por Kozak.
} 
modalização do discurso literário. Tal instância, configurada como focalizador externo, realiza o papel de mediador entre as falas de Molina e Valentín no plano do texto narrativo. Obviamente, esse focalizador se faz presente através das já referidas notas de rodapé, mas ele está posicionado fora da diegese, pois tais notas não interferem no universo diegético, mas, sim, na narrativa como um todo, ou seja, na maneira pela qual os fatos são apresentados no fio do discurso que sustenta textualmente a articulação do enredo. Funcionando como subsídio para o leitor, elas indicam os vetores ideológicos fundamentais para se compreender o crescimento dos personagens no decorrer da diegese narrativa. Molina, um homem que se constrói no gênero feminino, tendo como suporte para tal construção apenas a imagem da mulher submissa de Hollywood, consegue reconhecer-se como sujeito, adentrando inclusive a esfera pública do poder (quando aceita levar as informações dadas por Valentín para o grupo revolucionário). Valentín, por sua vez um revolucionário nascido na classe burguesa, consegue libertar-se dos preconceitos de gênero e sexualidade de sua classe de origem, aprendendo com Molina que não há uma correspondência direta entre homossexualidade e gênero feminino:

- ¿Y todos los homosexuales son así?

- No, hay otros que se enamoran entre ellos. Yo y mis amigas somos mu-jer [sic]. Esos jueguitos no nos gustan, esa son cosas de homosexuales. Nosotras somos mujeres normales que nos acostumbramos con hombres (Puig, 1994, p. 207).

Pode-se, finalmente, construir um esquema que ilustre o funcionamento dessa narrativa: tem-se um focalizador externo (FE), não perceptível na diegese romanesca, que delega plenos poderes aos personagens. É possível então formalizar os diferentes níveis de focalização ${ }^{8}$ da seguinte maneira:

1) Focalizador externo não perceptível [Molina]: por ocasião das falas de Molina, pois nesses momentos o focalizador dá

\footnotetext{
8 A categoria focalização, bem como seus desdobramentos, e a oposição entre um focalizador perceptível e um focalizador não perceptível aqui mobilizada é distinta da reflexão sobre o foco narrativo tornada clássica nos estudos de narratologia por Gérard Genette $(1972 ; 1995 ; 1998)$. A reflexão aqui feita alinha-se com os postulados narratológicos de Mieke Bal (1997). Ainda sobre a questão da narratologia e do estatuto do focalizador em contraste com o narrador, conferir Genette (1982; 2004) e Bal (2004).
} 
completa autonomia de ação para o personagem Molina, que atua como focalizador interno à diegese.

2) Focalizador externo não perceptível [Valentín]: por ocasião das falas de Valentín, pois em tais situações o focalizador retira a autonomia de Molina, delegando este estatuto a Valentín.

3) Focalizador externo perceptível [manifesto na voz que enuncia as notas de rodapé]: consciência anônima, erudita e onisciente, que age de fora da narrativa, incluindo toda uma reflexão teórica sobre a homossexualidade nas margens da narrativa ficcional.

O terceiro nível de focalização, ao contrário do que possa parecer em uma leitura mais superficial, não contradiz o princípio da autonomia dos personagens mencionado anteriormente. Inversamente, ele aponta para um focalizador que reconhece as especificidades subjetivas de cada um deles. Estando fora da diegese e tendo acesso aos pensamentos dos personagens, ele interfere na construção da diegese em determinados momentos, dando ao leitor acesso aos pensamentos de Molina - como no advento da narração do segundo filme, pois tal relato ocorre apenas na mente de Molina, sob a forma de monólogo interior (Puig, 1994, p. 104-118) e de Valentín - quando o focalizador dá acesso ao sonho do guerrilheiro, no qual o leitor tem acesso a sua concepção de mulher ideal (Puig, 1994, p. 128-133).

Destarte, a instância focalizadora termina por se configurar como um lugar outro, como um terceiro espaço ou, ainda, tal como afirma Homi K. Bhabha (1998), como um entrelugar, no qual é possível se pensar tanto as estruturas de dominação relativas à exploração econômica (expressas pelas crenças de Valentín) quanto as estruturas de dominação da heteronormatividade (representadas pelo esforço de Molina para fazer com que Valentín compreenda que, ainda que tenha nascido homem, optou por ser socialmente um sujeito do gênero feminino). A ênfase dada por Molina na questão do ser e portar-se como mulher, somadas aos conhecimentos da divisão sexual do trabalho (advindas das leituras marxistas-socialistas de Valentín) levam ainda à compreensão da situação da mulher em uma sociedade cujas premissas são os poderes do capital, do gênero masculino e da heteronormatividade. 
Após tais considerações, fica evidente que a reinvenção dos lugarescomuns do cinema e do melodrama feitas por Manuel Puig em El beso de la mujer araña, assim como o apagamento da presença de uma instância narrativa marcada na diegese romanesca, não são meramente informações estilístico-formais de cunho estético. São, antes de tudo, estratégias políticas de legitimação de uma modalização do discurso literário que permitem explorar as complexas inter-relações das categorias classe, gênero e desejo sexual na narrativa literária (Alós, 2009; 2010; 2011a; 2011b).

\section{Da (des)construção do gênero e do desejo ao estabelecimento de uma ética da alteridade}

Analisada a construção da diegese e o funcionamento das estratégias narrativas do romance, é possível averiguar as formas pelas quais são construídas as identidades sexuais dentro de El beso de la mujer araña. Ao reelaborar a noção de dispositif desenvolvida por Michel Foucault em Histoire de la sexualité (1976) a partir de um olhar feminista, Teresa de Lauretis formula a ideia de uma tecnologia do gênero pautada nas seguintes premissas: i) gênero é representação; ii) representar o gênero é construí-lo; iii) tal construção é um processo contínuo disseminado nas práticas sociais; e iv) a construção do gênero dá-se, paradoxalmente, por ocasião de sua própria desconstrução.

Se o gênero é representação, isso implica considerar que os papéis sociais, comportamentos e atitudes dos sujeitos sociais estão extremamente vinculados aos modos pelos quais estão representados nos artefatos culturais. Desta maneira, tudo aquilo que é considerado aprioristicamente como sendo pertencente ao universo masculino ou ao universo feminino só o é porque reiteradas representações do gênero assim o cristalizaram. Isso permite pensar que as nossas concepções de gênero não são categorias transcendentais e imutáveis, mas, sim, construções historicamente erigidas na cultura. Neste sentido, El beso de la mujer araña é extremamente representativo, pois não se configura como uma narrativa que legitima essas construções estagnadas do masculino e do feminino; ao contrário, traz os gêneros representados enquanto um conjunto de práticas, que por vezes desestabilizam o contínuo sexo-gênero-desejo. 
Molina, por ocasião dos primeiros capítulos da narrativa, mostra-se conformado com a premissa de que o lugar da mulher é o espaço privado, no qual se sujeita aos caprichos do marido. Ao final da narrativa, após um longo aprendizado com Valentín, compreende a importância da luta política, agindo na esfera pública como um sujeito autônomo. Valentín, por sua vez, desestabiliza suas concepções de mulher ideal de tal forma que aceita o intercurso sexual com Molina, estabelecendo um vínculo afetivo. Cabe ressaltar que, tal como fica evidente nas páginas 219 a 230 da obra de Puig, é Valentín que toma a iniciativa de acariciar Molina quando este está triste, e tais carícias iniciais dão vazão a um intercurso sexual completo, que por sua vez dá origem a um envolvimento afetivo entre os dois.

Chega-se então à segunda premissa de Teresa de Lauretis, a qual afirma que representar o gênero é construí-lo. Se pensarmos em Molina (particularmente no início da narrativa) como um homossexual alienado, isso se dá porque as mulheres representadas nos filmes hollywoodianos são submissas enquanto mulheres, e de tudo abrem mão pelo enlace afetivo heterossexual. Tais representações de gênero funcionam como tecnologias de subjetivação, que levam Molina a crer que para cumprir bem seu papel de mulher deve aceitar uma concepção até certo ponto masoquista da relação afetiva heterossexual: "la gracia está en que cuando un hombre te abraza, le tengas un poco de miedo" (Puig, 1994, p. 247).

Isso se comprova quando Molina fala de Gabriel, um homem casado pelo qual se apaixona antes de ser encarcerado. Molina constrói a si mesmo, como enunciador, de acordo com as convenções de gênero utilizadas pelas narrativas fílmicas hollywoodianas. Em outras palavras, Molina assume uma identidade performativa: através da linguagem ritualizada, ele não está simplesmente remontando a eventos passados, mas também está modalizando fatos do passado na forma de um discurso. Um discurso que, por sua vez, produz efeitos no real, no momento mesmo de sua enunciação. Em outras palavras, Molina é um personagem que vai desestabilizando o contínuo lógico e causal que sustenta a naturalidade e a legitimidade da heterossexualidade enquanto única expressão do desejo e da sexualidade, tal como aponta Judith Butler (1990/1999 e 1993), e de acordo com a segunda premissa posta por Teresa de Lauretis em torno da questão das tecnologias de

\footnotetext{
${ }^{9}$ Utilizo, nesse trabalho, a edição comemorativa, publicada pela Routledge.
} 
gênero. Isso que dizer que, se o gênero é representação e tal representação é o próprio mecanismo de construção da categoria gênero, realizar uma (auto)representação de gênero que subverta o status quo é subverter a própria política de gênero.

Dessa maneira, a narrativa também mostra que é através de um processo contínuo de reiteradas práticas sociais, disseminadas no complexo cultural, que se dá a construção do gênero. A cada vez que Molina sublinha seu sentimento de identificação com as heroínas dos filmes, reforça a construção de gênero de acordo com os parâmetros heteronormativos que, ao mesmo tempo, constroem a mulher como sujeito que deve se submeter à dominação masculina e edificam a homossexualidade como sexualidade anormal e periférica, como expressão identitária de exceção, a qual justifica a norma heterossexual. $\mathrm{O}$ comportamento de Molina problematiza, através da figura do travesti, a questão da identidade de gênero tomada como "destino biológico". Dentro das normas culturais dominantes, nascer com um pênis ou com uma vagina equivale a estar condenado ao masculino ou ao feminino, respectivamente. Um indivíduo que não forje sua identidade de acordo com o dado biológico está, dentro da norma cultural dominante, condenado à perda de sua legitimidade, ao não reconhecimento de sua identidade e, muitas vezes, até mesmo à segregação social.

Entretanto, cabe lembrar o alerta feito por Donna Haraway (2000, p. 101) em "Manifesto ciborgue: ciência, socialismo e tecnologia no final do século XX": "o gênero, a sexualidade, a corporificação, a habilidade: todos esses elementos são reconstituídos na história. Por que nossos corpos devem terminar na pele?" Se o corpo ganha significado apenas quando lido pela cultura, o que impede um corpo - cujo dado biológico é masculino - de ser lido e interpretado como pertencente ao feminino, de viver e experienciar o mundo não como um homem, mas como uma mulher? Molina, ao viver e experienciar o mundo como uma mulher, demonstra a arbitrariedade de se definir a identidade de gênero a partir do sexo biológico. Donde se pode depreender a necessidade normativa de pautar as formas de viver o corpo e os afetos em um sistema tão fechado de identidades?

Questionando tais premissas, Valentín e Molina estabelecem um vínculo pautado em uma ética da alteridade. Tal como afirma de Lauretis em sua terceira premissa, o gênero é um processo contínuo e disseminado através das práticas sociais. Ora, o cinema, para Molina, 
funciona como uma prática que constrói os gêneros: os galãs e as heroínas dos filmes interpelam Molina, oferecendo modelos de subjetividade. Com o passar do tempo, as contradições levam Valentín a um deslocamento, pois ele reconhece introjetados em si mesmo os valores machistas da classe burguesa, passando então a uma nova concepção de identidade sexual e de gênero, desconstruindo a lógica dominante. Ao desconstruir tal lógica (como no momento do intercurso sexual entre Valentín e Molina, ou quando Valentín descreve seu companheiro como uma mulher-aranha), paradoxalmente eles estão construindo representações de gênero. $O$ que materializa a quarta premissa de Teresa de Lauretis na textualidade do romance de Manuel Puig: questinando o status quo e estabelecendo novas relações eróticoafetivas, eles ao mesmo tempo desconstroem (identidades binárias pautadas no modelo heteronormativo) e constroem (novas possibilidades, mais fluidas e menos estáveis) identidades de gênero.

Isso não quer dizer que não exista como escapar dos papéis de gênero, de orientação sexual ou de afetividade estabelecidos por uma sociedade heteronormativa: tal como sugere o romance de Manuel Puig, a questão não está em inverter os pólos - seja colocando o feminino no topo de uma relação hierárquica, seja elegendo a homossexualidade como alternativa sexual e afetiva privilegiada -, mas, sim, em questionar os papéis rigidamente estabelecidos. Tal como Valentín afirma: "cada vez me convenzo más de que el sexo es la inocencia misma" (Puig, 1994, p. 224). De acordo com Deborah Britzman:

Precisamente da mesma forma que por muitas e contraditórias razões, não faz sentido discutir o que "causa" a heterossexualidade, também não faz nenhum sentido - nem mesmo como um projeto político - discutir as "causas" da homossexualidade. Nenhuma identidade sexual existe sem negociação ou construção. Não existe, de um lado, uma identidade heterossexual lá fora, pronta, acabada, esperando para ser assumida e, de outro, uma identidade homossexual instável, que deve se virar sozinha. Em vez disso, toda identidade sexual é um constructo instável, mutável e volátil, uma relação social contraditória e não finalizada (Britzman, 1996, p. 74).

Ora, não cabendo uma discussão sobre as "causas" ou "origens" da homo ou heterossexualidade, em que sentido contribuiriam as notas do romance de Manuel Puig com um projeto de desestabilização de categorias de gênero? A questão é que, no decorrer de suas notas, 
percebe-se que estas são enunciadas por um focalizador externo à diegese. Este mesmo focalizador é um sujeito que simpatiza ao mesmo tempo com a subversão do gênero e da sexualidade performativizada por Molina, e com os ideais políticos revolucionários de Valentín. Ao se observar as últimas notas de Puig, evidencia-se que o focalizador do romance colabora para o estabelecimento deste espaço intervalar entre a homossexualidade e a luta do proletariado, buscando a possibilidade de negociar interesses comuns e construir alternativas identitárias. Observe-se um trecho da última destas notas, ao final do romance:

Aquí es conveniente señalar los trabajos recientes de la doctora danesa Anneli Taube, como Sexualidad y revolución, donde expresa que el rechazo que un niño muy sensible puede experimentar con respecto a un padre opresor - símbolo de la actitud masculina autoritaria y violenta -, es de naturaleza consciente. El niño, en el momento que decide no adherirse al mundo que le propone ese padre - la práctica con armas, los deportes violentamente competitivos, el desprecio de la sensualidad como atributo femenino, etc.-, está tomando una determinación libre, y más aún, revolucionaria, puesto que rechaza el rol del más fuerte, del explotador. Ahora bien, ese niño no podrá vislumbrar en cambio que la civilización occidental, aparte del mundo del padre, no le proporcionará otro modelo de conducta, en esos primeros años peligrosamente decisivos - de los 3 a los 5 años sobre todo - que el de su madre. El mundo de la madre - la ternura, la tolerancia, las artes - le resultará mucho más atractivo sobre todo por la ausencia de la agresividad; pero el mundo de su madre, y aquí es donde la intuición del niño fallaría, es también el de la sumisión, puesto que ella forma pareja con un hombre autoritario, el cuál sólo concibe la unión conyugal como una subordinación de la mujer al hombre. En el caso de la niña que decide no adherirse al mundo de la madre, la actitud se debe en cambio a que rechaza el rol de la sometida, porque lo intuye humillante y antinatural, sin imaginar que excluido ese rol, la civilización occidental no le propondrá otro que el del opresor. Pero el acto de rebelión de esa niña y ese niño resultaría una muestra de valentía y dignidad, indiscutible (Puig, 1997, p. 209-10).

Ao estabelecer a relação entre a narrativa e os paratextos, percebe-se que esse focalizador está plenamente consciente de que a falta de modelos identitários é uma das motivações da alienação dos homossexuais. Não havendo possibilidades identitárias outras que não os papéis de gênero 
heterossexuais, o resultado seria uma imitação desses padrões pelos homossexuais. Em outras palavras, os homens homossexuais tenderiam a assumir o papel de passividade e submissão da mulher na sociedade patriarcal (representada pela mãe), enquanto as mulheres homossexuais tenderiam a desenvolver um comportamento mais agressivo, anárquico e violento. Nessa mesma nota, há a referência da importância do movimento feminista para a alteração deste quadro, contribuindo para a desconstrução - dentro das relações homossexuais - do modelo opressoroprimido de afetividade, o que indica a colaboração dos movimentos feministas para a conscientização de gays e lésbicas.

Eis os eixos de uma ética da alteridade: não aceitando nem o papel de submisso nem o de opressor, a relação entre Molina e Valentín sugere um novo tipo de afetividade. Nesta, os dois sujeitos colocam-se não mais em uma disposição hierárquica (heterossexual-homossexual ou masculinofeminino e, por metonímia, opressor-oprimido), mas, sim, um ao lado do outro, invertendo a lógica binária que subordina sempre o segundo elemento ao primeiro. Valentín não permite a Molina que se deixe humilhar; Molina, por sua vez, faz com que Valentín reformule suas noções a respeito das mulheres, dos prazeres sexuais e das identidades de gênero. $O$ guerrilheiro urbano que afirma no início do romance que os prazeres do sentido perturbam o engajamento na luta revolucionária não é mais o mesmo que afirma ser o sexo a própria inocência.

\section{Referências}

ALÓS, Anselmo Peres (2002). O eu, o outro e a ética da alteridade: um diálogo intertextual entre Fernando Pessoa e Caio Fernando Abreu. Caligrama: revista de estudos românicos, Belo Horizonte, v. 7, p. 23-38, jul. Disponível em: https://goo.gl/p5UzXu. Acesso em: 31 ago. 2012.

ALÓS, Anselmo Peres (2009). Heterotopias do desssossego: literatura e subversão sexual na América Latina. Cerrados, Brasília, v. 27, p. 231-249. Disponível em: https://goo.gl/pQJApo. Acesso em: 20 ago. 2012.

ALÓS, Anselmo Peres (2010). Narrativas da sexualidade: pressupostos para uma poética queer. Estudos feministas, Florianópolis, v. 18, n. 3, p. 837-864. Disponível em: https://goo.gl/CYCfgB. Acesso em: 20 de julho de 2012. 
ALÓS, Anselmo Peres (2011a). Gênero, epistemologia e performatividade: estratégias pedagógicas de subversão. Estudos feministas, Florianópolis, v. 19, n. 2, p. 421-449. Disponível em: https://goo.gl/uOY0HO. Acesso em: 1º jul. 2012.

ALÓS, Anselmo Peres (2011b). Prolegomena queer: gênero e sexualidade nos estudos literários. Cadernos de letras da UFF, Niterói, n. 42, p. 199-217. Disponível em: https://goo.gl/dGRZfs. Acesso em: 20 ago. 2012.

ALÓS, Anselmo Peres (2013). A letra, o corpo e o desejo: masculinidades subversivas no romance latino-americano contemporâneo. Florianópolis: Mulheres.

BAKHTIN, Mikhail (1993). A cultura popular na Idade Média e no Renascimento: o contexto de François Rabelais. Tradução de Yara Frateschi Vieira. São Paulo: Hucitec; Brasília: UnB.

BAKHTIN, Mikhail (1997). Marxismo e filosofia da linguagem. 8. ed. Tradução de Michel Lahud e Yara F. Vieira. São Paulo: Hucitec.

BAKHTIN, Mikhail (1981). Problemas da poética de Dostoiévski. Tradução de Paulo Bezerra. Rio de Janeiro: Forense Universitária.

BAL, Mieke (Ed.) (2004). Narrative theory: critical concepts in literary and cultural studies. London: Routledge, $4 \mathrm{v}$.

BAL, Mieke (1997). Narratology. 2nd edition. Toronto: The University of Toronto Press.

BHABHA, Homi K. (1998). O local da cultura. Belo Horizonte: Editora da UFMG.

BOOTH, Wayne (1983). The rethoric of fiction. 2nd ed. Chicago: University of Chicago Press.

BRITZMAN, Deborah (1996). O que é esta coisa chamada amor: identidade homossexual, educação e currículo. Educação \& realidade, Porto Alegre, v. 21, n. 1, p. 71-95, jan./jun.

BUTLER, Judith (1993). Bodies that matter: on the discursive limits of "sex". London: Routledge.

BUTLER, Judith (1997a). Excitable speech: a politics of the performative. London: Routledge.

BUTLER, Judith (1997b). The psychic life of power. Stanford: Stanford University Press.

BUTLER, Judith (1999). Gender trouble. 10th anniversary edition. London: Routledge. 
BUTLER, Judith (2001). Corpos que pesam. In: LOURO, Guacira Lopes (Org.). O corpo educado: pedagogias da sexualidade. 2. ed. Belo Horizonte: Autêntica, p. 151-172.

BUTLER, Judith (2003). Problemas de gênero. Tradução de Renato Aguiar. Rio de Janeiro: Civilização Brasileira.

CHATMAN, Seymour (1978). Story and discourse. Ithaca: Cornell UP.

CHATMAN, Seymour (1990). Coming to terms. Ithaca: Cornell UP.

DE LAURETIS, Teresa (1984). Alice doesn't: feminism, semiotics, cinema. Bloomington: Indiana University Press.

DE LAURETIS, Teresa (1987). Tecnologies of gender. Bloomington: Indiana University Press.

FOUCAULT, Michel (1976). Histoire de la sexualité: la volonté de savoir. Paris: Gallimard.

GENETTE, Gérard (1972). Figures III. Paris: Seuil.

GENETTE, Gérard (1982). Palimpsestes: la littérature au second degrée. Paris: Seuil.

GENETTE, Gérard (1995). Discurso da narrativa. Lisboa: Vega.

GENETTE, Gérard (1998). Nuevo discurso del relato. Madrid: Cátedra.

GENETTE, Gérard (2004). Métalepse, de la figure à la fiction. Paris: Seuil.

HARAWAY, Donna (2000). Manifesto ciborgue: ciência, tecnologia e feminismosocialista no final do século XX. In: SILVA, Tomás Tadeu da (Org.). Antropologia do ciborgue: as vertigens do pós-humano. Belo Horizonte: Autêntica, p. 37-130.

HUTCHEON, Linda (1991). Poética do pós-modernismo: história, teoria, ficção. Tradução de Ricardo Cruz. Rio de Janeiro: Imago.

KINDT, Tom; MÜLLER, Hans-Harald (2006). The implied reader: concept and controversy. Translated by Alaistar Mathews. New York: Walter de Gruyter.

KOZAK, Claudia (1991). Una política del género. Cuadernos Americanos: nueva época, Méjico, año 5, v. 1, n. 25, p. 163-81.

PUIG, Manuel (1976/1994). El beso de la mujer araña. New York: Vintage Español.

RICE-SAYRE, Laura (1989). Dominação e desejo: uma leitura materialistafeminista de $O$ beijo da mulher-aranha de Manuel Puig. Ilha do Desterro, Florianópolis, n. 22, p. 13-28, $2^{\circ}$ sem. 
Recebido em março de 2016.

Aprovado em julho de 2016.

\section{resumo/abstract/resumen}

\section{El beso de la mujer araña: gênero, sexualidade e subversão}

Anselmo Peres Alós

Este trabalho pretende realizar uma leitura crítica do romance El beso de la mujer araña (1976), escrito pelo argentino Manuel Puig, a partir de uma perspectiva que questiona os arranjos e as representações de gênero e sexualidade dentro do universo diegético da narrativa. É a partir das categorias de focalização, cunhada por Mieke Bal, e de performatividade, elaborada no campo dos estudos feministas por Judith Butler, que se pretende sustentar a leitura desse romance como uma alegoria política da economia do corpo, do gênero e dos afetos, sustentáculos para a proposta de uma ética da alteridade como alternativa aos valores patriarcais e heteronormativos que subordinam as possibilidades identitárias de gênero e de expressão do desejo sexual.

Palavras-chave: gênero, sexualidade, focalização, performatividade, Manuel Puig, El beso de la mujer araña.

\section{El beso de la mujer araña: gender, sexuality and subversion}

\section{Anselmo Peres Alós}

This paper is a critical reading of Manuel Puig's El beso de la mujer araña (1976). It examines gender arrangement and representation in the diegetic universe of the narrative. Using Mieke Bal's theory of focalization and the concept of performativity, as proposed by Judith Butler, this work defends the idea that Puig's novel can be read as a political allegory of the economy of the body, of gender and of affect. These three elements are the basis to propose a new ethics of alterity as a counterpoint to patriarchal and heteronormative values that limit gender identity possibilities and the expression of sexual desire.

Keywords: gender, sexuality, focalization, performativity, Manuel Puig, El beso de la mujer araña. 


\section{El beso de la mujer araña: gênero, sexualidade y subversión}

Anselmo Peres Alós

Este trabajo pretende realizar una lectura crítica de la novela El beso de la mujer araña (1976), escrita por el escritor argentino Manuel Puig, a partir de una perspectiva que cuestiona los órdenes y las representaciones de género y de sexualidad dentro del universo diegético de la narrativa. Es a partir de las categorias de focalización, acuñada por Mieke Bal, y de performatividad, elaborada dentro del campo de los estúdios feministas por Judith Butler, que se pretende sustentar la lectura de esta novela como una alegoria política de la economía del cuerpo, del género y de los afectos, bases para la propuesta de una ética de la alteridad como alternativa a los valores patriarcales $\mathrm{y}$ heteronormativos que subordinan las posibilidades identitárias de género y de expresión del deseo sexual.

Palabras clave: género, sexualidad, focalización, performatividad, Manuel Puig, El beso de la mujer araña. 